San Jose State University

SJSU ScholarWorks

Master's Theses

Master's Theses and Graduate Research

1995

\title{
Occupational therapy techniques in the treatment of infants exposed to cocaine in utero : a pilot study
}

Irene E. Brown

San Jose State University

Follow this and additional works at: https://scholarworks.sjsu.edu/etd_theses

\section{Recommended Citation}

Brown, Irene E., "Occupational therapy techniques in the treatment of infants exposed to cocaine in utero : a pilot study" (1995). Master's Theses. 1124.

DOI: https://doi.org/10.31979/etd.edyc-mta2

https://scholarworks.sjsu.edu/etd_theses/1124

This Thesis is brought to you for free and open access by the Master's Theses and Graduate Research at SJSU ScholarWorks. It has been accepted for inclusion in Master's Theses by an authorized administrator of SJSU ScholarWorks. For more information, please contact scholarworks@sjsu.edu. 


\section{INFORMATION TO USERS}

This manuscript has been reproduced from the microfilm master. UMI films the text directly from the original or copy submitted. Thus, some thesis and dissertation copies are in typewriter face, while others may be from any type of computer printer.

The quality of this reproduction is dependent upon the quality of the copy submitted. Broken or indistinct print, colored or poor quality illustrations and photographs, print bleedthrough, substandard margins, and improper alignment can adversely affect reproduction.

In the unlikely event that the author did not send UMI a complete manuscript and there are missing pages, these will be noted. Also, if unauthorized copyright material had to be removed, a note will indicate the deletion.

Oversize materials (e.g., maps, drawings, charts) are reproduced by sectioning the original, beginning at the upper left-hand comer and contimuing from left to right in equal sections with small overlaps. Each original is also photographed in one exposure and is included in reduced form at the back of the book.

Photographs included in the original manuscript have been reproduced xerographically in this copy. Higher quality $6^{\prime \prime} \times 9^{n}$ black and white photographic prints are available for any photographs or illustrations appearing in this copy for an additional charge. Contact UMI directly to order.

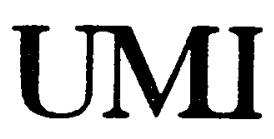

A Bell \& Howell Intormation Company 


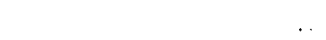




\title{
Occupational Therapy Techniques in the Treatment of Infants Exposed to Cocaine In Utero: \\ A Pilot Study
}

\author{
A Thesis \\ Presented to \\ The Faculty of the Department of Occupational Therapy \\ San Jose State University \\ in Partial Fulfillment \\ of the Requirements for the Degree \\ Master of Science
}

by

Irene E. Brown

December, 1995 
UMI Number: 1377215

OMI Microform 1377215

Copyright 1996, by UMI Company. All rights reserved.

This microform edition is protected against unauthorized copying under Title 17, United States Code.

\section{UMI}

300 North zeeb Road

Ann Arbor, MI 48103 
(C) 1995

Irene E. Brown

ALL RIGHTS RESERVED 
APPROVED FOR THE DEPARTMENT OF OCCUPATIONAL THERAPY

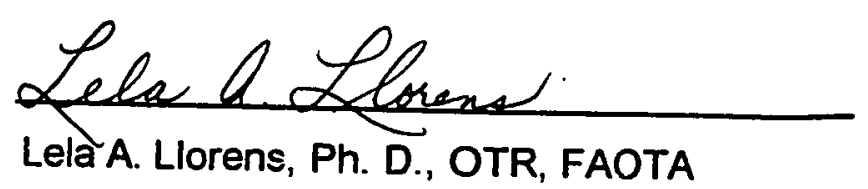

Heidi Mottugh Pendleton Heidi McHugh Pendleton, M. A., OTR

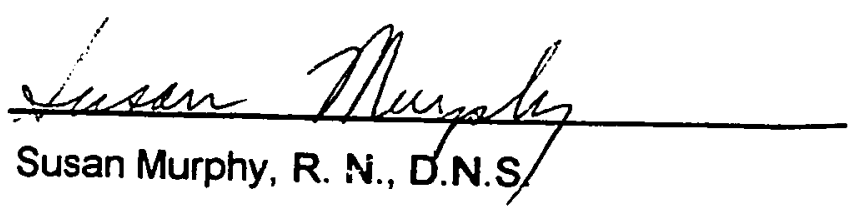

APPROVED FOR THE UNIVERSITY

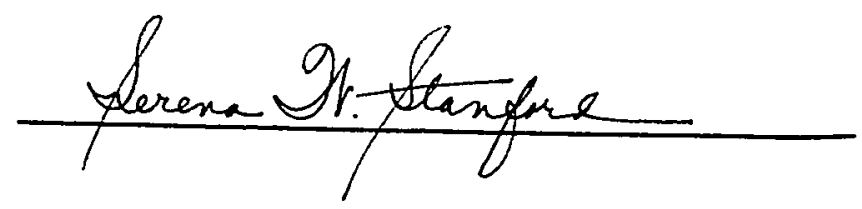




\begin{abstract}
Occupational Therapy Techniques in the Treatment of Infants Exposed to Cocaine In Utero: A Pilot Study
\end{abstract}

by Irene E. Brown

This research examined the assessment and intervention techniques reported by occupational therapists in the treatment of infants exposed prenatally to cocaine and how the occupational therapist integrated the infant's family and environment into the overall care of the infant.

The research was conducted via telephone interview. Findings revealed that occupational therapists use a variety of evaluation tools, objective and standardized assessment techniques, and a variety of treatment techniques and approaches. Some were contingent upon the treatment setting within which the occupational therapist was based. Most occupational therapists noted the importance of interaction with the infant's family or caretaker including involvement of the caretaker in the infant's treatment sessions. 


\section{ACKNOWLEDGMENTS}

Special thanks to my committee for their time and attention to detail, to my family for their support, and to my husband for his knowledge and patience. 


\section{TABLE OF CONTENTS}

ABSTRACT iv

ACKNOWLEDGMENTS v

LIST OF TABLES Ix

CHAPTER 1: INTRODUCTION 1

$\begin{array}{ll}\text { Purpose } & 1\end{array}$

$\begin{array}{ll}\text { Statement of the Problem } & 1\end{array}$

$\begin{array}{ll}\text { Research Questions } & 2\end{array}$

$\begin{array}{ll}\text { Definitions } & 2\end{array}$

$\begin{array}{ll}\text { Assumptions } & 4\end{array}$

$\begin{array}{ll}\text { Limitations } & 5\end{array}$

Significance of the Study $\quad 5$

CHAPTER 2: LITERATURE REVIEW 9

Introduction 9

Symptomatology of Infants Exposed to Cocaine in Utero 9

Opposing View of the Effects of Cocaine on Infants in Utero 12

$\begin{array}{ll}\text { Confounding Factors } & 13\end{array}$

Family and Infant Assessment and Intervention 14

$\begin{array}{ll}\text { Occupational Therapy Assessment and Intervention } & 18\end{array}$

Spatiotemporal Adaptation Frame of Reference 20

$\begin{array}{ll}\text { Summary } & 24\end{array}$ 
CHAPTER 3: RESEARCH METHODOLOGY AND RESULTS 27

$\begin{array}{ll}\text { Research Questions } & 27\end{array}$

Sample $\quad 27$

$\begin{array}{ll}\text { Instrument } & 27\end{array}$

$\begin{array}{ll}\text { Procedure } & 28\end{array}$

$\begin{array}{ll}\text { Data } & 28\end{array}$

$\begin{array}{lr}\text { Demographics } & 29\end{array}$

Interview Question One: Referrals 29

Interview Question Two: Exposure 31

$\begin{array}{ll}\text { Research Data } & 31\end{array}$

Interview Question Three: Assessments 31

Interview Question Four: Intervention 34

Interview Question Five: Treatment Techniques Unique 39

Interview Question Six: Family and Environment 42

Answers to Research Questions $\quad 47$

CHAPTER 4: DISCUSSION, PROFESSIONAL IMPLICATIONS, RECOMMENDATIONS FOR FURTHER RESEARCH

$\begin{array}{ll}\text { AND SUMMARY } & 49\end{array}$

$\begin{array}{ll}\text { Discussion } & 49\end{array}$

Research Question One: Assessments $\quad 49$

Research Question Two: Intervention 52

Research Question Three: Family and Environment 53

vii 
Professional Implications and Recommendations for Further Research

Summary

56

REFERENCES

59

APPENDICES

63

Appendix A Verbal Consent Form

63

Appendix B Interview Questions

64 


\section{LIST OF TABLES}

Table 1: Method of Infant Referral Reported by Occupational

Therapists from Different Treatment Settings

Table 2: Method of Determining Infant Cocaine Exposure

Reported by Occupational Therapists

Table 3: Assessment Instruments Reported by Occupational

Therapists from Different Treatment Settings

Table 4: Treatment Methods Reported by Occupational

Therapists from Different Treatment Settings

Table 5: Methods of Involving Family or Caretaker in Caring

for the Cocaine Exposed Infant Reported by Occupational

Therapists from Different Treatment Settings 


\section{CHAPTER 1 \\ INTRODUCTION}

Purpose

The purpose of this pilot study was to identify assessment and intervention techniques utilized by occupational therapists in the treatment of infants exposed to cocaine in utero.

\section{Statement of the Problem}

Ten years ago cocaine was thought of as a safe, euphoria producing drug that was tried by many people in whom an addiction was produced (McCanceKatz, 1991). Although the incidence of the abuse of alcohol, marijuana, heroin, and other substances with a potential for abuse by women of child-bearing age has not changed over the last ten years, the incidence of cocaine use has increased as its popularity among the general public has increased (Chasnoff, 1988). The popularity of cocaine became widespread in 1985. In 1990 the first wave of infants exposed to cocaine entered school. Studies on the long-term effects of cocaine exposure are still incomplete but it is believed that the effects are life-long and have a definite impact on academic achievement. At birth infants who are exposed to cocaine are at risk for developmental and learning disabilities (Elliott, 1991). In addition, many authors have commented on the social impact of infant cocaine exposure including immediate hospital costs due to medical complications associated with cocaine exposure and the cost of placing these infants in foster homes due to the unhealthy environment produced by the addictive lifestyles of the parents. Though actual figures are not available, additional costs are expected once these children reach school and 
require special education and/or special attention due to developmental and learning disabilities.

It is believed that an effective form of intervention to address this problem would be prevention in the form of providing education and pre-natal care to the most "at risk" mothers. However, when infants continue to be born with cocaine exposure, early infant intervention is the best answer. Occupational therapists can provide skilled intervention for these infants based on their knowledge of development, neurology, and ability to integrate the family and the environment into treatment. Information concerning the care of these infants has not generally been included in the occupational therapy literature. In order to make habilitation and rehabilitation available for at risk infants, it is important to determine the techniques currently used for assessment and intervention and provide such information for other occupational therapists.

\section{Research Questions}

The research questions to be answered were:

1) What are the occupational therapy assessment techniques being performed on infants who have been exposed to cocaine in utero?

2) What are the intervention techniques used by the occupational therapists in the treatment of infants that have been exposed to cocaine in utero?

3) How are the family, caretaker, environment, and home situation considered in the occupational therapist's treatment of the infant exposed to cocaine in utero?

Definitions

The following definitions were generated for this study.

Environmental modification - Changing an individual's physical surroundings, such as a home, in order to encourage a certain behavior. 
Extensor muscles - Muscle groups involved in motions of extension or straightening of a joint.

Extensor tone - An increase in tone of the muscles involved in extension causing an imbalance in the muscles and a decrease in muscle control.

Flexor muscles - Muscle groups involved in motions of flexion or bending at a joint.

Infant behavior states-Stages of arousal through which a normal infant will cycle, including: sleep (deep or light sleep); wakefulness (drowsy, quiet alert or active alert); and crying (Schneider, Griffith, \& Chasnoff, 1989).

Infant exposed to cocaine in utero - An infant whose mother ingested some form of cocaine during her pregnancy. Infant identified for this study via caretaker history or infant urinalysis at birth or shortly after birth that indicated cocaine exposure.

Infant state control - The ability of a normal infant to move smoothly from one behavioral state to another (Schneider et al., 1989).

Lower extremities - The legs, feet, and toes.

Occupational therapy assessment technique - A standardized or nonstandardized instrument or procedure administered to the client prior to beginning treatment to determine initial need for and goals of treatment. Occupational therapy intervention techniques - Methods utilized by the occupational therapist in performing treatment on a client.

Overstimulation - Usually referring to sensory overload or the inability of the individual to process the amount of sensory information given, generally resulting in distress and a negative behavioral response. 
Primitive (abnormal) reflexes - Reflexes normally present at earlier stages of development which are not integrated into higher motor learning patterns as in a normal child through the course of development.

Prone - Lying on one's stomach

Supine - Lying on one's back.

Tremors - A postural tremor is the oscillation of the body or a limb when the individual attempts to hold the limb steady against gravity (Urbscheit, 1990). Upper extremities - The arms, hands, and fingers.

Vestibular / proprioceptive stimulation - The neurological system that is involved with head and body equilibrium. It can be stimulated by linear acceleration and deceleration in the horizontal and vertical planes; it can be stimulating, facilitated by fast rocking or relaxing, inhibited by slow rocking (Umphred \& McCormack, 1990).

\section{Assumptions}

It was assumed that the occupational therapists who were interviewed and have stated that they have provided therapy for infants exposed to cocaine in utero have done so and that therapists, as stated, were working with cocaine exposed infants in Southern California. It was assumed that the stated treatment methods actually have been utilized by the therapists interviewed with infants exposed to cocaine in utero and are not a compilation of what would be believed to be useful. It was assumed that the diagnosis for the infants exposed to cocaine in utero was correct. Also, it was the belief of the author that infants exposed to cocaine in utero must be treated early in order for treatment to be effective and that treatment must involve not only the infant but also the condition of the caregiver and care giving environment. The author's 
assumptions are in agreement with those of Denhoff (1981) concerning the treatment of children with developmental disabilities in that (1) infancy is a crucial period and intervention only will be effective if started in early life, (2) the appropriate maternal and infant behavior is contingent upon a positive interaction between mother and child, and (3) a disabled infant must be managed as a total person with an emphasis on physical, mental, and social elements. Further, the author believes that occupational therapy has a role in the assessment and treatment of infants exposed to cocaine in utero.

\section{Limitations}

This study was limited by sample size and geographical location. A larger sample size would provide a better overall picture of common treatment methods and practices used by occupational therapists for infants exposed to cocaine in utero. This study was also limited by design. An "on the spot" telephone interview does not allow the interviewee time to prepare answers to the questions and information may have been omitted. This study did not test infant outcomes or the effectiveness of the treatment in improving the medical condition, function, or coping of the infant or the family on a long or short term basis. This study did not examine influences and roles of other treatment team members or their treatment methods for infants exposed to cocaine in utero. Thus the overall treatment of the infant was not assessed but was limited to procedures administered by occupational therapists.

Significance of the Study

Because the popularity of cocaine has increased since 1985 the incidence of infants exposed to cocaine in utero has risen. Research on the effects of cocaine on the exposed infant is limited though many researchers stress that the 
effects may be profound and life-long and that early intervention is indicated. Effects on the infant exposed to cocaine in utero may include an increase in primitive reflexes, limb stiffness, irritability, tremulousness, rapid mood changes, poor movement patterns, poor infant-parent bonding, and resistance to being held or cuddled (Chasnoff, 1991; McCance-Kaiz, 1991; Schneider et al., 1989; Windeguth \& Urbano, 1989). Caring for an infant with developmental and behavioral deficits can be a challenge for the most patient and nurturing caregiver. In a family where a drug addiction has taken precedence over care of the infant and the nurturing of the family, there can be a high incidence of abuse and neglect. This can become complicated even further when the infant becomes a ward of the court and increased dollars are required from the government to care for the infant and child.

Chiu, Vaughn, and Carzoli (1990) reported that the hospital costs of treating a cocaine exposed infant were approximately double those of a non-drug exposed infant. Phibbs, Bateman, and Schwartz (1991) stated that the high costs of caring for cocaine exposed infants are accrued not only from medical needs but from the social aspects of maternal cocaine. These can include the costs of caring for "boarder babies" or infants remaining in the hospital for social evaluation or of foster care placement after they are medically stable (p.1521).

Once infants exposed to cocaine in utero reach school age additional problems can arise. Chasnoff (1991) commented that little information on the long term effects and costs of cocaine or other drug exposure is available. Cocaine exposed infants are at risk for developmental delay and one must consider the environment in which the child is being raised and the drug use patterns of the pregnant woman. A child with a developmental delay and 
behavioral problems will have difficulty learning and thriving in a traditional school setting because the developmental and behavioral skills were never integrated during the early years to prepare for the demands of the school environment. As a result, children may require special attention and may have special educational needs which can place a burden on society. Phibbs et al. and Chiu et al. commented that if maternal cocaine use has prolonged effects on infants, ultimate costs may be much larger than the short term economic consequences when these children enter the school system, though further study on the long term effects of cocaine exposure is required.

The most cost effective way to deal with this problem would be through prevention. Public education courses that help prevent drug use during pregnancy and programs that can reach pregnant women who are at highest risk for drug abuse would be most cost effective (Chasnoff, 1988; Phibbs et al., 1991). In many ways society (through organizations and the media) has addressed this problem with the goal of educating the public on the effects of fetal cocaine and other drug exposure. Many mothers, however, continue to "fall through the cracks" because of their personal circumstances and give birth to infants exposed to cocaine. Schneider et al. (1989) reported that though many drug abuse programs exist, programs for pregnant drug abusers are less prevalent. It is at this point in the continuum that occupational therapists can make the greatest impact with early intervention for infants that have been exposed to cocaine in utero.

In early infant intervention occupational therapists have the professional background in human development, neurological rehabilitation, and behavioral management that is important in the treatment of infants and children with 
neurological deficits. In addition, occupational therapists recognize the importance of and have expertise for environmental modification and family and caregiver training. This component is especially important due to the delicate nature of the infant/caregiver interaction and need for education in order for parenting to be successful. The occupational therapy literature does not presently contain information concerning the treatment of infants exposed to cocaine in utero although it is reported that treatment for these infants by occupational therapists is presently being provided. It is the belief of the author that occupational therapy has a role in the assessment and treatment of infants exposed to cocaine in utero and that in order for treatment to be effective it must not only involve the infant but the condition of the caregiver and the caregiving environment. 


\section{CHAPTER 2}

\section{LITERATURE REVIEW}

\section{Introduction}

The literature review for this study is organized into four major sections.

The first section describes the symptomatology of the infant exposed to cocaine in utero including motor control patterns, infant behaviors, and long term effects of infant cocaine exposure. The second section reviews opposing view points of researchers who found that prenatal cocaine exposure has little effect on infants' growth and development. This section also addresses confounding factors which make discriminating the sole effects of cocaine difficult. The third section examines infant and family assessment techniques and interventions that are in place used by a variety of professionals in the care of infants exposed to cocaine in utero. The fourth section examines the role of occupational therapy in the assessment and treatment of infants exposed to cocaine in utero. This section also reviews the occupational therapy conceptual frame of reference that guided this research.

\section{Symptomatology of Infants Exposed to Cocaine in Utero}

Chasnoff (1988) and Elliott (1991) commented on the small amount of information available regarding the effects of infants exposed to drugs and the extent to which learning disabilities and inappropriate social behaviors are due to cocaine exposure in utero. Singer et al. (1994) reported that both animal and findings from human studies have suggested that through the mechanisms of vascular disruption and hypoxia, cocaine exposure can have a significant negative impact on the developing fetus. Several researchers reported on the symptoms that infants exposed to cocaine in utero may display. These include: 
an increase in primitive reflexes, limb stiffness, irritability, tremulousness, rapid mood changes, poor movement patterns, poor infant-parent bonding, and resistance to being held or cuddled (Chasnoff, 1988; McCance-Katz, 1991; Schneider et al., 1989; Windeguth \& Urbano, 1989). When tested, cocaine exposed infants performed more poorly in cognitive and motor skills than the non-exposed group and the overall developmental scores for cocaine exposed infants were in the at risk range (Singer et al., 1994). Schutter and Brinker (1992) noted that the behavioral symptomatology of withdrawal in the newborn is very similar to the behavior associated with infants with central nervous system damage.

Schneider et al. described in detail the symptomatology of infants exposed to cocaine in utero. Cocaine exposed newborns (one month) showed depressed interactive abilities and poor state control when compared to non-exposed infants. At age four months, infants exposed to cocaine in utero frequently exhibited upper extremity tremors, increased extensor muscle tone in the lower extremities, and abnormal primitive reflex patterns. Schneider et al. found that infant motor control is affected with prenatal cocaine exposure.

A normal four month old infant is very flexible and active physically which is necessary for the infant to discover his/her own body and in developing body image. In the supine position (on the back), a normal infant will reach out with his/her hands, finger one hand with the other, kick with the legs reciprocally, and play and explore the hands and feet. In order to create balance in the muscles and to facilitate proper strength and postural control, both flexor and extensor muscle groups develop without one dominating the other. 
In contrast, Schneider et al. found that the four month old cocaine exposed infant is not as flexible as the non-cocaine exposed infant. In the supine position, the cocaine exposed infant's movements are jerky and stiff. Tremors in the upper extremity can impede reaching for objects and thus the development of eye hand coordination. Problems with reciprocal kicking can make exploring the lower body difficult. Exploring the body is important for the development of body image and learning the environment. Increased extensor tone especially in the lower extremities can encourage abnormal alignment of body parts that can impede development and postural control.

Schnieder et al. (1989) described behavioral difficulties with infants exposed to cocaine in utero related to problems of state control. Cocaine exposed infants have difficulty moving smoothly from one behavioral state to another. A cocaine exposed infant tends to change rapidly from one extreme state (e.g. deep sleep) to another (e.g. crying). Due to difficulties with state control, many newborn cocaine exposed infants are initially incapable of responding appropriately to the caregiver. These infants will have difficulty processing auditory and visual stimuli and need assistance from the caregiver to stay calm. Also, those infants who are able to reach alert states usually can do so only for short periods and then begin to show signs of distress such as gaze aversion, increased respiration, and disorganized motor activity.

Several authors (Allen, Palomares, DeForest, Sprinkle, \& Reynolds, 1991; Elliott, 1991 ; Schneider et al., 1989; Singer et al., 1994) studied the behavioral and developmental patterns of school age children who had been exposed to cocaine in utero. These children were found to lag significantly in development compared to children who were not exposed in utero. It was found that these 
children have an inability to deal with many different stimuli at once, a low frustration tolerance, difficulty structuring information, poor concentration, poor ability to interact with others, and an inability to cope in an unstructured environment.

Opposing View of the Effects of Cocaine on Infants in Utero Studies by a few individuals have reported that cocaine exposure has little effect on the infant behaviorally or developmentally. Richardson and Day (1991) reported that infants exposed to cocaine were not different from a comparison group of non-cocaine exposed infants in terms of growth parameters and morphological development. Also, they found no behavioral differences when the cocaine exposed infants were tested using the Brazelton Neonatal Behavioral Assessment Scale. However, urine assays to detect the presence of cocaine were not available on this sample of women so there may have been cocaine users in the comparison group. Also, very few of the women used cocaine throughout their pregnancy which may have reduced the cocaine exposed infants' symptomatology. In addition, Zuckerman and Frank (1994) warned that the poor developmental outcome of cocaine exposed infants is much less conclusive than suggested. They suggested that many complex issues contribute to the uncertainty of the prenatal effects of cocaine exposure. These include: inaccurate identification of users, uncertain measurement of the dose and timing of infant cocaine exposure, sample selection bias, inability to control for confounding variables, identification of appropriate comparison populations, and selection of sensitive outcome measures. 


\section{Confounding Factors}

Schutter and Brinker (1992) suggested that infants exposed to cocaine in utero do not differ behaviorally from other groups of neurologically impaired infants. They did express; however, that infants exposed to cocaine have the added disadvantage of exposure to polydrug abuse and a dysfunctional caregiving environment focused on drug use and not on infant care. Allen et al. (1991) and Singer et al. (1994) noted that many cocaine abusers are polydrug users, who abused marijuana, alcohol, tobacco, and other drugs in conjunction with cocaine. Mothers who have abused cocaine have reported smoking cigarettes that contained a mixture of tobacco, marijuana, and cocaine. Chasnoff (1988) noted that it is important in the evaluation of risk factors for the newborn that the effects of these secondary drugs of abuse be considered. Other factors Which were discussed that may influence infant development and involve maternal lifestyle include poor nutrition and failure to seek prenatal care (Allen et al., 1991; Schutter \& Brinker, 1992; Windeguth \& Urbano, 1989). Schutter and Brinker cited several studies which showed that $60-70 \%$ of women who abused cocaine received no prenatal care. In addition, Schutter and Brinker noted that the direct effects of cocaine are difficult to determine because the amount and duration of drug use by pregnant women is related to the effect on the fetus and the only current and consistent method of reporting cocaine usage is via selfreport. Schutter and Brinker believed that women are often unwilling to discuss or underestimate their use of drugs during pregnancy because of fear or other factors. In addition, the lack of a legal mandate for systemic laboratory testing for drugs as a part of routine obstetric care or upon delivery made identification of the effects of cocaine on the infant difficult. 
Bauer (1991) raised the issue that because of confounding factors it would be difficult to distinguish the effects of cocaine exposure from exposure to other drugs. In addition, later physical and emotional development of the infant may be affected by the home environment and the parent-child relationship. Chasnoff (1988) argued that due to the chaotic nature of the drug-seeking environment, poor parenting skills, and the infants' neurobehavioral deficits, environmental factors including socioeconomic, maternal-infant relationship, and maternal psychopathology and personality should be taken into account when one is evaluating the effects of cocaine exposure on a child's development. Several researchers stressed that children of substance abusing families often develop in unstable, dangerous environments. If the mother of a cocaine exposed infant continues to use cocaine, a non-traditional pattern of parent-child interaction could occur where the craving for the drug could be of utmost importance and the care of the infant compromised (Allen et al., 1991; Bauer, 1991).

Several authors agree that the home environment is a critical determinant of infant outcome and that children of deprived social environments carry a burden of later impairment. The negative responses of the infant can initiate a negative cycle where the poorly organized behavior of the cocaine exposed infant will not facilitate the optimal caregiving pattern to facilitate the infant's recovery. This pattern may predispose later abuse which has been seen in other high-risk groups (Schneider et al., 1989; Singer et al., 1994; Zuckerman \& Frank, 1994).

Family and Infant Assessment and Intervention

Before considering treatment for the infant exposed to cocaine in utero several authors have emphasized the importance of accurate and thorough infant and family assessments. Schneider et al. (1989) believe that whenever 
prenatal exposure to cocaine is suspected by medical personnel a urine toxicology screening should be performed. Bauer (1991) warned medical personnel not to dismiss cocaine abuse on the basis of appearance, age or socioeconomic status. Smith and Deitch (1987) and Windeguth and Urbano (1989) found that it was important and argued for the inclusion of questions in the intake interview regarding family history, lifestyle behavior, substance abuse, and other factors of the home environment when the mother arrives for prenatal care. Also, these researchers stressed the importance of developing a comfortable and trusting relationship with the mother and encouraged the use of a non-judgmental approach.

Hanft (1988) stated that comprehensive assessments are important and should examine development in physical, cognitive, and psychosocial domains. Schneider et al. (1989) suggested more specific infant assessments such as the Brazelton Neonatal Behavioral Assessment Scale (Brazelton, 1994). Beyond the newborn period, motor development could be assessed using the Movement Assessment of Infants (MAI) which provides qualitative and quantitative assessment of motor development in the first year of life (Asher, 1989).

Hanft (1988) noted that young children are totally dependent on their families for care and nurturing. If the proper care is not provided, the child could be at risk for developmental delay. In addition, Hanft believed that the current emphasis in early intervention programs was based on family-centered care. It is a model that is focused on family services that enable parents and caregivers to help their child grow and develop.

Schneider et al. (1989) identified intervention goals and extensive intervention plans for babies exposed to cocaine in utero in the newborn and 
infancy periods. The goal of intervention for the newborn exposed to cocaine in utero included increasing periods of alertness so the appropriate infant-parent bonding can occur. Schneider et al. (1989) stressed that proper handling of the infant is essential to improve the infant's state control and to facilitate the appropriate motor patterns. Techniques include swaddling in a blanket and slow rocking to calm the infant and to bring the infant to a visually alert state. Once the infant is calm, the caregiver can talk to the infant, provide visual stimulation (i.e. eye contact), and provide playful interactions with the infant. Swaddling the infant in a semiflexed position is also suggested to encourage infant hand to mouth activities. Neonatal hydrotherapy has also been shown to reduce irritability and improve motor control. Hydrotherapy consists of placing the infant in a small tub of water, $99 \mathrm{~F}$ to $101 \mathrm{~F}$ and encouraging appropriate infant body positioning and hand to mouth activity. Infant positioning in the nursery can also facilitate appropriate motor responses in the cocaine exposed infant. The cocaine exposed infant can be placed on his/her side with the head, spine, and lower body flexed with the hands toward the center of the body; this will bring the infant away from the abnormal hyperextended position frequently observed with cocaine exposed infants. To help achieve this positioning, the health professional or family caregiver can place rolled up cloth diapers between the infant's legs and along the spine to maintain posture while allowing some freedom of movement (Schneider et al., 1989).

Placing the infant in positions to encourage effective play behavior is an important part of intervention to encourage motor, cognitive, and psychosocial development. Placement in the supine position, will make it difficult for the cocaine exposed infant to play with his/her hands and feet due to increased 
extensor tone. Caregivers can facilitate play behavior by lifting the infant's pelvis and flexing the legs toward the chest to encourage kicking movements. The infant's arms and hands can be brought down and forward to allow grasping for objects. Infants should not be left in the supine position for long periods of time because the effects of gravity can be tiring and difficult to overcome. In the prone position (on the stomach) the infant should be enticed to move by placing colorful toys beside the infant to encourage reaching and grasping. Sitting activities are an appropriate developmental activity from about five months of age. Cocaine exposed infants tend to push backwards when sitting or standing which is called extensor thrusting. This can be avoided by holding the cocaine exposed infant in a more flexed position with the hips bent and arms forward.

Schneider et al. (1989) emphasized parent education as being of great importance to enhance normal infant development and to ensure a strong parent-infant bond. Schneider et al. further stressed that parent education should begin early and the infant strengths should be emphasized as well as addressing weaknesses. Specific techniques for intervention included educating parents and caregivers on common signs of infant distress and overstimulation. Signs of distress may include "yawning, gaze aversion, sneezing, hiccuping, spitting up, color changes, and crying" (p. 33). Schnieder et al. stressed that caregivers should be taught positioning and handling techniques and caregivers should perform a return demonstration of all learned techniques. Caregivers should be taught to be observant of the infant's cues during interactions and how to respond appropriately. 
Occupational Therapy Assessment and Intervention

The occupational therapy literature does not specifically addréss assessment and intervention for the infant exposed to cocaine in utero. Several authors have stressed the importance of the involvement by occupational therapists with early intervention and have cited programs that focus on familycentered care. Gorga (1989) noted that occupational therapists work with infants in early intervention to facilitate function by enhancing motor control, sensory modulation, and social-emotional development. The American Occupational Therapy Association (1986) described occupational therapy in early intervention as services for children "who are biologically or environmentally vulnerable from birth to preschool" (p. 535). Intervention is focused on facilitating development of sensorimotor skills, cognition, communication, physical and emotional health and adaptive behavior of the child and enhancing care-giver capabilities. In addition it was stressed that occupational therapists are especially valuable in early intervention because of their knowiedge of nervous system development and function. Goals of early intervention included: expanding the competence of the child and assisting the family in their ability to manage the child. In addition, Gorga (1989) and Hanft and Humphry (1989) noted that occupational therapy services for the infant should include family services to aid the adult caregiver in the care and facilitation of the development of the child.

With the enactment of Public Law 99-457 there was a shift in the focus of early intervention from a child-centered approach to a more comprehensive system involving children and their families (Dunn, 1989). Hanft (1988) and Humphry (1989) have noted that occupational therapists have recognized the importance of the parent-child relationship to the development of the child and 
that occupational therapy provides services that affect both the development of the child and the parent-child relationship. Hanft has also acknowledged the "need to develop collaborative and supportive relationships with families and other caregivers as a primary aspect of occupational therapy intervention" (p. 729). Schaaf and Mulrooney (1989) suggested a family-centered framework for utilization by occupational therapists that "places the child and the family in the context of their life environments" (p. 745). The authors stated that by using this model, treatment is not only focused on child intervention but also works with environmental adaptations that will enhance the competence of the family and the child. Schaaf and Mulrooney noted that the model works by allowing occupational therapists to work with the values, needs, habits, and skills of the family and the child in their environment. Sameroff and Fiese (1990) suggested a systems perspective for early intervention based on grouping intervention strategies into three broad categories: remediation, that places the child at the focus of intervention and involves direct efforts to change the child via medical, therapeutic or educational interventions; redefinition, that involves altering the parent's perception of the child's behavior and altering the parent's response to a particular behavior; and reeducation, that involves teaching parents different methods to interact with their children. An occupational therapist skilled in early intervention techniques could aid in the treatment of the infant exposed to cocaine in utero using this perspective.

Though the occupational therapy literature does not specifically address intervention for the infant exposed to cocaine in utero, Denton (1986) examined intervention for failure to thrive infants who have a similar presentation of symptoms and signs as the cocaine exposed infant. Denton described failure to 
thrive as a diagnosis associated with children whose rate of growth is deficient for their age. Symptoms of a failure to thrive child with central nervous system damage that are similar to those of a crack-cocaine exposed infant include: atypical social responses, delayed development, increased irritability, unwillingness to be cuddled, or a negative reaction to touch.

Denton (1986) presented an occupational therapy protocol based on three years of clinical practice during which comprehensive team evaluations were performed with a large failure to thrive population. Denton suggested that his protocol be used in the assessment and the development of treatment strategies in failure to thrive infants. The protocol Denton described included clinical observations such as: caretaker-infant interactions in the areas of play (methods, mood, and affect of the infant) and feeding (infant history, caretaker procedures, and environmental setup); therapist-infant interactions in the areas of infant overall responsiveness, level of irritability, avoidance responses, posturing/ movement patterns, and oral motor function; and a developmental assessment choosing from the Revised Gesell Developmental Schedules (Gesell, 1975), Sewell Early Education Developmental Profile, or the Vulpe Assessment Battery (as sited in Denton, 1986).

\section{Spatiotemporal Adaptation Frame of Reference}

With the assessment and intervention of infants exposed to cocaine in utero the focus of intervention is on enhancing infant development which has been delayed secondary to cocaine exposure. Though the severity of the impairment is contingent upon the timing and the amount of cocaine exposure to the fetus, many authors have sited the risk of developmental delay among infants exposed to cocaine in utero and the potential risk of cocaine exposed infants requiring 
special education when they reach school age. Many authors have agreed that early intervention with infants who are at risk for developmental delay is the key to preventing further developmental delay and to integrating these children into non-adapted school environments. It is the belief of the author that occupational therapists have a role in facilitating the development of infants exposed to cocaine in utero and that this role may be explained through the occupational therapy frame of reference, spatiotemporal adaptation. An occupational therapy frame of reference is a set of ideas or concepts that guide the practice of occupational therapy for the treatment of physical or psychosocial dysfunction.

The model of spatiotemporal adaptation introduced by Gilfoyle, Grady, and Moore (cited in Kielhofner, 1992) presented ideas from motor control and sensory integration models which they organized into a framework for use in determining assessment and intervention for children with developmental delay. The model stressed the importance of movement and movement based activities in the process of adaptation to the environment. Spatiotemporal adaptation is based on the concept that a child's developmental course is influenced by environmental experiences of movement and activity. The theory of spatiotemporal adaptation grew out of the observation of how normal children learn motor skills and how developmentally delayed children deviate from this process. The authors of this model presented it as a framework for thinking about the normal process of spatiotemporal adaptation, how dysfunction in this process occurs, and how intervention can be used to prevent further developmental delay or facilitate the normal development of at risk infants and children (Gilfoyle, Grady, \& Moore, as cited in Kielhofner, 1992). 
In the normal process of development, an infant and child will facilitate their own development by engaging in play behavior. Play is the primary way in which children engage in motor behavior that facilitates development. Movement provides experiences from which a child comes to know objects in the environment and relationships to others. Movement is important not only for physical development but also for psychological and social development. There is a dynamic link between central nervous system maturation, the child's behavior, the physical and emotional environment, and the course of development. The physical and emotional environment provides the child with challenges that promote change in adaptation and in play behavior. Gilfoyle, Grady, and Moore (cited in Kielhofner, 1992), conceptualized the development of a child as an ever widening spiral represented in the child's mastery of an ever-increasing range of skills and larger circle of environmental situations. A normal child will use related components from previous behaviors as a base to approach more challenging situations and then adapt to develop a more mature response. The environment presents situations that promote positive stress in children. Stress is essential to development because it forces the child to evoke high level functions to cope with the stress. When a normal child experiences stress, the child attempts to resolve the problem by problem solving through different ways of accomplishing the goal. By modifying their approach to the problem, children expand their knowledge base of how to solve certain types of problems and develop higher level functions which serve more challenging purposes.

According to Gilfoyle, Grady, and Moore (cited in Kielhofner, 1992), the source of spatiotemporal dysfunction is damage to the central nervous system. 
Nervous system damage disorganizes the child's performance of activities. Without performance in functional activities, the nervous system is deprived of a means by which development can proceed. As a result of damage to the central nervous system, the child experiences distress in response to environmental challenges. Distress interferes with all aspects of adaptation and may manifest by improper processing of sensory information causing sensory overload in the child as with infants exposed to cocaine in utero. Distress may also affect accommodation and association so that the child is unable to use learned behavioral responses to help adapt to their environment. Children with central nervous system damage are unable to move to higher levels of development because they cannot effectively integrate or adapt simpler patterns of behavior into new stressful situations. These children try to use lower level functions to achieve higher level activities which is not effective and interferes with the spiral of adaptation process and can eventually lead to developmental delay.

The basis of occupational therapy intervention, according to this model, is the concept of neuroplasticity. Neuroplasticity is the nervous system's ability to undergo changes as a result of sensorimotor experience. The normal process of development depends on the child's active participation in the play environment. The occupational therapist provides opportunities to reach this goal with children with central nervous system damage by structuring the environment for the child to participate in play without experiencing distress. The authors identified certain parameters that must be met in the treatment environment: 1) the child must be placed in the most optimal physical and emotional state to respond to the environment, and 2) environmental challenges must be within range of the child's abilities. The modes of therapeutic action then will include: 
1) preparation, that involves preparing both the child (posturing, normalizing postural tone or increasing range of motion) and the environment; 2) facilitation, that involves providing the necessary stimulus or assistance to elicit a certain adaptive response; and 3 ) adaptation, which is the process by which a child is challenged to organize his/her behaviors to meet environmental requirements and promote development. The therapist chooses activities carefully to promote appropriate sensory stimulation to facilitate motor behavior. The activity enhances previously unresponsive brain cells and enhances neural organization to facilitate development. Activities should be purposeful so that the child's attention is directed toward the purpose or goal and the median of treatment is play. This allows the lower level abilities to be integrated and adapted into higher level functions. The goal of treatment is for each child to reach their highest potential. Goals of intervention can include prevention, remediation, or adjustment to dysfunction depending on the child (Gilfoyle, Grady, \& Moore (cited in Kielhofner, 1992).

\section{Summary}

A review of the current literature offered an overview of the symptomatology and care of the cocaine exposed infant. Several authors (Chasnoff, 1988; McCance-Katz, 1991; Schneider et al., 1989; Windeguth \& Urbano, 1989) have reported on the negative effects of in utero cocaine exposure. Schneider et al. (1994) described in detail the problems seen with infants exposed to cocaine in utero. Cocaine exposure can effect motor control patterns, infant behaviors, and psychosocial development that can lead to developmental delay. Authors Shutter and Brinker (1992), found that cocaine exposed infants presented in similar ways to infants with central nervous system damage. In addition, other 
authors (Allen, Palomares, DeForest, Sprinkle, \& Reynolds, 1991; Elliott, 1991 ; Schneider et al., 1989; Singer et al., 1994) studied the effects of cocaine exposure in school age children. These children were found to lag significantly in development when compared to non-cocaine exposed infants which made success in non-adapted school settings difficult.

Some authors (Richardson \& Day, 1991) found that cocaine exposure had little to no effect on the developing fetus. In addition, Zuckerman and Frank (1994), warned about the uncertain measurement of cocaine exposure (as to timing and amount) and the inability to control confounding variables such as smoking and alcohol use, frequently used in conjunction with cocaine by cocaine using women in deciding on the effects of cocaine exposure in infants.

Before considering treatment for the infant exposed to cocaine in utero, many authors (Bauer, 1991; Hanft, 1988; Schneider et al., 1989; Smith \& Deitch, 1987; Windeguth \& Urbano, 1989) stressed the importance of thorough infant and family assessments. Assessments may include a urine toxicology screen and an intake interview with the parents or infant caregiver. Infant assessments should be comprehensive and examine development in physical, cognitive, and psychosocial domains. Schneider et al. (1989) identified extensive treatment plans and goals for infants exposed to cocaine in utero including facilitating motor control, infant-caregiver bonding, and infant play behavior. Including the family and caregiver in the intervention was stressed as of utmost importance. The occupational therapy literature did not specifically address assessment and intervention techniques for infants exposed to cocaine in utero. Several authors, however, have stated the importance of occupational therapy's role in early intervention and programs which focus on enhancing infant motor control, 
sensory modulation, and social development of infants with developmental delay or at risk for developmental delay (Gorga, 1989; Hanft \& Humphry, 1989). In addition, the occupational therapy literature has stressed the importance of integrating the family and caretaker in the care of the infant with a focus on family centered care (Dunn, 1989; Hanft, 1988; Humphrey, 1989; Schaaf \& Mulrooney, 1989).

The occupational therapy frame of reference which guided this research was the theory of spatiotemporal adaptation, developed by Gilfoyle, Grady, and Moore (cited in Kielhofner, 1992). These authors presented a model for occupational therapy intervention for infants and children with developmental delay as a result of central nervous system damage. The model stressed the importance of movement and movement based activities in the process of adaptation to the environment. This model can be applied to infants exposed to cocaine in utero as a framework for the assessment and treatment by occupational therapists. 


\section{CHAPTER 3}

\section{RESEARCH METHODOLOGY AND RESULTS}

A descriptive research study was conducted with a survey design using a structured telephone interview.

\section{Research Questions}

The research questions to be answered were:

1) What are the occupational therapy assessment techniques being performed on infants who have been exposed to cocaine in utero?

2) What are the intervention techniques used by the occupational therapists in the treatment of infants that have been exposed to cocaine in utero?

3) How are the family, caretaker, environment, and home situation considered in the occupational therapist's treatment of the infant exposed to cocaine in utero?

\section{Sample}

Seventeen registered occupational therapists participated in this study. Occupational therapists who participated in this study were employed in a hospital or outpatient setting in Southern California where treatment was provided for infants exposed to cocaine in utero.

Instrument

Six telephone interview questions were prepared by the researcher that allowed for answers to the research questions. Four questions addressed the research questions directly. The remaining two questions provided additional information regarding infant referral base and method of detecting infant cocaine exposure. The telephone interview questions were kept simple and number of interview questions kept to a minimum. This was done to keep the interview time short to promote greater participation by occupational therapists. 
interview questions kept to a minimum. This was done to keep the interview time short to promote greater participation by occupational therapists.

\section{Procedure}

Occupational therapists were recruited for the study by calling hospital and pediatric outpatient treatment facilities in Southern California which could yield potential participants. The procedure for recruitment of participants proceeded as follows: 1) The researcher called hospital and pediatric outpatient facilities and asked to speak with an occupational therapist; 2) The researcher stated her name, affiliation, and described the research study; 3 ) The researcher asked if any occupational therapists in the facility worked with infants who have been exposed to cocaine in utero; 4) When the researcher was permitted to speak with the occupational therapist, the researcher stated the conditions of the study and asked whether the occupational therapist would like to participate in the study. If he/she agreed, the researcher read the subject his/her rights (see Appendix A), and 5) Answers to interview questions were scribed by the researcher on a data collection sheet during the phone interview (see Appendix B). Content analysis was performed. Data were analyzed for frequency of response categories and frequency tables were constructed.

\section{Data}

The data presentation is organized by the responses to the interview questions. Six questions were included in the interview. Questions one and two yielded demographic information and provided insight into infant referral base and how infants were diagnosed with cocaine exposure. Questions three, four, five, and six yielded data to answer research questions. 


\section{Demographics}

Seventeen occupational therapists were interviewed for this study. They were recruited from two treatment settings. Eight occupational therapists were recruited from hospital based programs or neonatal intensive care units (NICU) and nine were recruited from outpatient settings.

\section{Interview Question One: Referrals}

How and from whom do you get a referral for an infant who has been exposed to cocaine in utero? Among the eight occupational therapists who were working in hospital based settings or the neonatal intensive care unit, seven of the eight reported receiving referrals for infants exposed to cocaine from the physician. The one occupational therapist interviewed who did not mention a physician directly stated that it was a "referral from the unit from the case manager." Other methods of referral reported, each stated by one occupational therapist included: (a) referral from community agencies, (b) referral if the mother has a history of cocaine exposure, (c) physician standing order for preterm infants in general, although they may not be drug exposed, (d) nurse referral, and (e) the occupational therapist doing his/her own case finding.

Of occupational therapists who worked in outpatient settings, eight of the nine reported receiving referrals from the Developmental Disabilities Center or regional center. Two of the nine occupational therapists interviewed reported receiving referrals from physicians; one reported receiving referrals by word of mouth, and one reported receiving referrals from the neonatal intensive care unit (see Table 1). 
Table 1

Method of Infant Referral Reported by Occupational Therapists from Different Treatment Settings $(\underline{N}=17)$

\begin{tabular}{lcc}
\hline & \multicolumn{2}{c}{ Treatment Setting } \\
\cline { 2 - 3 } Referral Base & $\begin{array}{c}\text { Hospital } \\
\mathrm{n}=8\end{array}$ & $\begin{array}{c}\text { Outpatient } \\
\mathrm{n}=9\end{array}$ \\
\hline Physician & 7 & 2 \\
$\begin{array}{l}\text { Developmental Disabilities Center } \\
\text { or Regional Center }\end{array}$ & 0 & 8 \\
Case Manager & 1 & 0 \\
Community Agencies & 1 & 0 \\
Standing Physician Order for Preterm Infants & 1 & 0 \\
Physician (if mother has a history of cocaine) & 1 & 0 \\
Nurse & 1 & 1 \\
OT does own case finding & 0 & 1 \\
NICU & 1 & 0 \\
\hline
\end{tabular}




\section{Interview Question Two: Exposure}

How do you know that the infant has been exposed to cocaine? Of the total number of occupational therapists interviewed, 15 of the 17 reported receiving information on whether the infant was exposed to cocaine in the medical record. This information was stated as "urine toxic screening - test positive." In addition to the medical record, 3 of the 17 occupational therapists interviewed reported using parental interviews to find out information regarding the infant's exposure to cocaine, 2 of the 17 reported that they used clinical observation when checking for cocaine exposure in the infant. One occupational therapist interviewed commented that "infants are mainly exposed to a variety of drugs and there is a question to when they are exposed." Another occupational therapist commented that identifying whether the infant has been exposed is "iffy and if the mom or baby acts strange, the physician will do a drug screen of the baby, mother, or both" (see Table 2).

\section{Research Data}

\section{Interview Question Three: Assessments}

What sort of initial assessments do you perform? Occupational therapists working in hospital settings reported using both generalized and standardized assessment techniques. The most frequently reported generalized assessment techniques included: (a) behavioral response assessment including state control, biorhythms, level of irritability, and infant self calming reported by six of eight occupational therapists; (b) motor development assessment including muscie tone, range of motion, and reflex evaluation reported by five of eight occupational therapists; (c) oral motor/feeding assessments including suck, swallow, breathing, effort into nipple feeding, and feeding tolerance reported by 
Table 2

Method of Determining Infant Cocaine Exposure Reported by Occupational Therapists $(\underline{N}=17)$

Method

Occupational Therapists

Medical Record

15

Parent Interview

Clinical Observation 
four of eight occupational therapists; and (d) clinical observation, reported by five of eight occupational therapists. Other generalized assessment techniques included infant responses to sensory impact that included touch, movement, vestibular response, visual and auditory input; and infant autonomic response behavior that included startle response and tremulous movement. Each assessment was mentioned by one of the eight respondents.

Standardized assessments reported by occupational therapists working in hospital settings were as follows. Three of eight reported using the Brazelton Behavioral Assessment Scale. Two of eight reported using the Assessment for Pre-term Infant Behaviors (APIB), The Dubawitz, The Morgan Neurodevelopmental Assessment, and Bayley Scales of Infant Development. One of eight reported using each of the following assessments: Infant Behavioral Scale, Miller Assessment for Preschoolers, Movement Assessment of Infants, and The Gesell Developmental Test.

A negative comment concerning use of standardized assessments was given by one occupational therapist who stated, "I do not use the Brazelton Behavioral Assessment Scale because it is too hard on the babies and the babies change too fast" but mentioned; however, that he/she used the Brazelton upon discharge from the hospital. Another occupational therapist interviewed in this category stated that he/she used portions of the APIB but it was "too long to use for preemies initially."

For occupational therapists treating from an outpatient setting, the most frequently reported assessment tool was clinical observation reported by all nine of the respondents. Other generalized assessment tools reported by occupational therapists included: (a) developmental assessment reported by 
three of the nine; (b) sensory processing assessment reported by three of the nine; (c) motor assessment reported by two of the nine; and (d) feeding assessment reported by one of the nine. In addition, three of the nine occupational therapists interviewed reported using a questionnaire as an assessment tool that asks about the infant's behaviors and motor observations and is completed by the infant's parents or foster parents.

The most frequently reported standardized assessment tools used by occupational therapists based in outpatient settings included: (a) The Gesell Developmental Tests reported by five of the nine occupational therapists interviewed, (b) Developmental Programming for Infants and Young Children (Michigan) reported by four of the nine, and (c) Bayley Scales of Infant Development reported by four of the nine. Assessment tools reported less frequently included: Miller Assessment for Preschoolers reported by two occupational therapists interviewed; and the Peabody Developmental Motor Scales, the Dubowitz and Denver Developmental Screening Test, each reported by one occupational therapist interviewed.

When data from all interviews were tabulated, the most frequently reported assessment tool was clinical observation which was reported by 14 of the 17 occupational therapists interviewed (see Table 3).

\section{Interview Question Four: Intervention}

What intervention strategies or treatment methods do you use? The treatment approaches reported by occupational therapists interviewed who work in hospital based settings included Neurodevelopmental Treatment (NDT), Developmental approach, and Sensory Integration (SI). Six of the eight occupational therapists interviewed reported using NDT as a treatment 
Table 3

Assessment Instruments Reported by Occupational Therapists from Different

Treatment Settings $(\underline{N}=17)$

Treatment Setting

Assessment

Hospital Outpatient

$\underline{n}=8 \quad \underline{n}=9$

Standardized Assessments

Brazelton Behavioral Assessment Scale

3

0

Assessment for Preterm Infant Behaviors

2

0

The Dubawitz

2

1

Morgan Neurodevelopmental Assessment

2

0

Bayley Scales of Infant Development

2

4

Infant Behavioral Scale

1

0

Miller Assessment for Preschoolers

1

2

Movement Assessment of Infants

1

0

Gesell Developmental Test

1

5

Michigan

0

4

Peabody

0

1

Denver Developmental Screening Test

0

1 


\section{Generalized Assessments}

Behavioral Assessment

6

0

Motor Assessment

5

2

Feeding Assessment

4

1

Clinical Observation ${ }^{\star}$

$5^{\star}$

$9^{*}$

Sensory Response

1

3

Autonomic Response

1

0

Developmental Assessment

0

3

Parent Questionnaire

0

3

* Most frequently reported assessment overall 
approach. One occupational therapist interviewed stated that NDT was his/her "primary focus of treatment"; two stated that they used NDT "some of the time." Five of the eight occupational therapists interviewed reported using the Developmental approach. Three stated that the Developmental approach was his/her "primary treatment approach." Two of the eight occupational therapists reported using Sensory Integration. One occupational therapist stated that Sensory Integration was his/her "primary treatment approach." Another occupational therapist stated he/she used this approach "some of the time."

In addition to these treatment approaches many treatment techniques were reported by occupational therapists who work from hospital settings. Of the twelve total treatment techniques mentioned by the occupational therapists interviewed, four were stated most frequently and included: (a) infant calming techniques, (b) feeding techniques, (c) parent education, and (d) infant external environmental control. Calming techniques were reported by eight of the eight occupational therapists interviewed and included: "swaddling, state control, and rocking." Feeding techniques were reported by five of the eight occupational therapists interviewed and were described by one as "swaddling the infant so they are in a confined position to bring control back with feeding-bring back a rhythm to them." Parent education was reported by five of the eight. Controlling the infant's external environment was mentioned by five of the eight occupational therapists interviewed and included "decreasing stimulus, dimming lights, and decreasing sound to promote minimal sensory input." One occupational therapist interviewed stressed the importance of this technique when he/she stated: "Look at the baby's behavior with the environment. If the baby is irritated find the most quiet place in the nursery. Use minimal handling; try to keep the baby calm; this 
may include sedation. Occupational therapy is [consistently] assessing the environment and [infant] coping skills in their environment and then adapts the treatment to [the infant's] behavior."

Other techniques mentioned less frequently by occupational therapists based in hospital settings included:(a) sensory processing techniques including tactile stimulation and deep pressure, reported by four of the eight; (b) infant self calming techniques including "bringing the thumb to the mouth," reported by three of the eight; (c) nursing education, reported by three of the eight occupational therapists interviewed; and (d) motor control, including "facilitating normal movement, normal reciprocal movement, positioning, and control of tone" reported by two of the eight. Other treatment techniques mentioned by only one of the eight occupational therapists interviewed included: Heidelise Als technique, massage, hydrotherapy-explained by this occupational therapist as "placing the infant in warm water in a dark quiet room," and behavior modification. In addition, four of the eight commented that all of the treatment techniques chosen depend on the infant and that "the intervention is contingency based or based on need" and "you use what works."

Negative comments regarding treatment approaches and treatment techniques were made by one occupational therapist interviewed when he/she stated that he/she used "no NDT" and "trying to teach self strategies (infant self calming techniques) usually does not work."

Of the occupational therapists based in outpatient settings, all nine of the occupational therapists interviewed reported using Sensory Integration (SI) as a treatment approach. Two occupational therapists reported that this was their primary treatment approach. Six of the nine occupational therapists interviewed 
reported using Neurodevelopmental Treatment (NDT) as a treatment approach. Five of the nine occupational therapists interviewed reported using a Developmental approach to treatment.

Treatment techniques reported included behavioral management techniques and calming techniques reported by two of the nine occupational therapists interviewed. Those techniques reported by one occupational therapist interviewed included: environmental modification, functional activities (reaching), parent education, feeding, and oral stimulation. In addition, three of the nine occupational therapists interviewed reported that the treatment techniques used were very individualized and adaptable. One occupational therapist interviewed commented on this when he/she stated: "you can't use a pure SI or pure NDT approach - you use a holistic approach, whatever suits the infant's needs."

Negative comments concerning treatment approaches and techniques included one occupational therapist who stated he/she did not use NDT "because no one here has NDT training." Upon examination of all treatment techniques reported, Neurodevelopmental Treatment (NDT) remained most reported treatment approach, 12 of the 17 occupational therapists interviewed (see Table 4).

\section{Interview Question Five: Unique Treatment Techniques}

Are the treatment techniques being used unique to the cocaine exposed infant population? Fourteen of the 17 occupational therapists interviewed stated that the treatment techniques being used were not unique to the cocaine exposed infant population. Comments made by the occupational therapists in response to this question were similar in nature and included: (a) "I would use these techniques with whomever seems appropriate. These techniques are 
Table 4

Treatment Methods Reported by Occupational Therapists from Different

Treatment Settings $(\underline{\mathbf{N}}=17)$

\begin{tabular}{lcc}
\hline Treatment Method & \multicolumn{1}{c}{ Treatment Setting } \\
\cline { 2 - 3 } & $\begin{array}{c}\text { Hospital } \\
\underline{n}=8\end{array}$ & $\begin{array}{c}\text { Outpatient } \\
\text { n }=9\end{array}$ \\
Treatment Approach & $5)^{\star}$ & 6 \\
Neurodevelopmental Treatment (NDT) & 5 & 5 \\
Developmental Approach & 2 & 9 \\
Sensory Integration & 5 & \\
\hline
\end{tabular}

Treatment Technique

Infant Calming

8

2

Feeding

5

1

Parent Education

5

1

Environmental Modification

5

1

Sensory Processing

4

0

Infant Self Calming

3

0

Nursing Education

3

0

Motor Control

2

0 


\begin{tabular}{lll} 
Heidelise Als & 1 & 0 \\
Infant Massage & 1 & 0 \\
Infant Hydrotherapy & 1 & 0 \\
Behavior Management / Modification & 1 & 2 \\
Functional Activities & 0 & 1 \\
Individualize treatment "use what works" & 4 & 3 \\
\hline
\end{tabular}

* Most reported treatment approach overall 
similar to those used with premature and hypersensitive infants." (b) "Not all infants [who are] cocaine exposed have problems; assessment is individualized. I would use similar techniques with [an infant with] neurological insult." (c) "I would use these techniques with any infant showing similar signs; cocaine or drug [exposed] babies are similar to [infants with] bronchopulmonary dysplasiaa chronic lung disease caused by prolonged ventilation." (d) "I would go by the principles of looking at the environment and try to adjust to meet the baby's needs." (e) "I would use similar techniques with other infants [for instance] with colic or with one [infant] who is unresponsive." (f) "Similar techniques are used with infants with developmental delay or neuromuscular problems." (g) "[cocaine exposed infants are] similar to many populations [such as infants with] developmental delay, autism, learning disabilities, and attention deficit disorder." Three of the 17 occupational therapists interviewed stated that the treatment techniques being used were unique to the cocaine exposed infant population. Comments made by interviewed occupational therapists in response to this question included: "They [cocaine exposed infants] present similarly to neurolabile colic infants with irritability, arching and stiffening up; except infants exposed to drugs are like that all the time and neurolabile colic infants only when they are irritable" and "a majority [of cocaine exposed infants] have sensory integration (SI) problems though there is a behavioral component, unlike the pure SI child."

\section{Interview Question Six: Family and Environment}

How is the infant's family, caretaker or environment considered? Family training and education were mentioned by all eight of the occupational therapists interviewed who were based in hospital settings. Comments made concerning 
the importance of family education were similar in nature and included: (a) "The family or caretaker is the primary place occupational therapy intervenes." (b) "I invite parents and/or foster parents to be part of the treatment session with a 'reciprocal interchange' to help the parent engage with the infant and work with environmental adaptations." (c) "Occupational therapy lets the parents know that the baby has been exposed and works with the parents on behavioral and mental implications of drug exposure." (d) "Here [at this facility] we have a team effort and the family is very involved; we work with families on feeding issues, social considerations, and home programs." (e) "I try to work with families to discuss infant needs and work on developmental techniques with the families." (f) "Parent and family education is a big part of neonatal care; [I deal with] isolated issues of weaknesses and strengths and make suggestions on how to deal with the infant. " (g) "Families are instructed during the treatment though only $10-20 \%$ come in to do the training." (h) "I involve the family to promote bonding with the infant and how to look for signs of stress. Regardless of the status of the mother it's important to get her in there. I treat the mom too, a lot of work with the mothers and the babies. Abuse and neglect are common and the mother many times is not aware of the baby's patterns. In treatment sessions we do home programs and watch the bonding strategies between mom and baby (I call this) 'mom and baby dance."

Five of the eight occupational therapists based in hospital settings commented on the concern for the infant's environment upon discharge from the hospital. Most occupational therapists who commented in this section appeared to note their frustrations: "a high percentage (of infants exposed to cocaine) go to foster care and are left to the wards of the court"; "99\% become wards of the 
court. It is then the county's responsibility to investigate how they are doing. Once they become wards of the court, occupational therapy has no control, zero follow-up, we lose them after they leave the hospital." "Needy mothers and needy babies are a bad combination. I try to work with that. It is difficult to get mothers to come back for follow-up, they go back to the same environment and a grouchy kid. Many go back to old habits and don't come back to treatment." "Once they leave the hospital we have little control over what will happen." One occupational therapist interviewed commented on home assessments: "I don't do home assessments. The Department of Children's Services is responsible for [assessing whether] the environment the infant lives in is safe."

Four of the eight occupational therapists based in hospital settings commented on the importance of occupational therapy's involvement with social services. The comments included: "We work with social work if the family is taking the child home. Many foster families in the area are trained to work with drug [exposed] babies." "Social work is a big part of working with the family and is an important part of occupational therapy. Social services is adjunct to our own service."

Of those occupational therapists based in outpatient treatment settings, eight of the nine occupational therapists interviewed stated that families were present during treatment sessions and were an important part of the team. Comments made by occupational therapists were very similar in nature and included: "The family is included in everything we do including home programs and recommendations on caring for the infant." "Family is an important part of the process and the team." "Ninety-five percent of the kids are in foster homes. Most are an important part of the assessment and treatment." "We have daily 
communication with parents, reactions to activities, and facilitation of home programs." "We work directly with the caregiver, someone is there $100 \%$ of the time being trained as well as working with the infant." "We do a lot of family training, we alter the environment to manage the baby better, and encourage families to call us if there are any problems". One occupational therapist had a negative comment concerning family training: "Occupational therapy does not intervene with families and caregivers. Contacting families are covered by other disciplines (counseling and administration). Occupational therapy has too much to do already" (see Table 5).

One question which was added midway through the study asked if occupational therapists felt there was improvement needed in the area of occupational therapist's interaction with families of infants exposed to cocaine in utero. Four occupational therapists of the 17 interviewed stated there was need for improvement. Comments included: "In general there have been cutbacks and we have less flexibility to work with the families and there are many problems with scheduling." "It is important that the family is involved and I would like to see more family involvement." "Foster homes are not always the answer. We need to improve education, improve prenatal care, and support more 'mommy and me' classes, intervention courses aimed at intervention with mothers and babies." Four of the 17 occupational therapists interviewed seemed to have mixed feelings concerning whether or not improvement was needed. Comments included: "More interaction with families would be difficult due to the increased rate of adoption of the infants (exposed to cocaine) and denial of the parents." "Yes and no. It depends on the family. At times occupational therapy and physical therapy are just baby-sitting." "It's hard to say whether we can do better. 
Table 5

Methods of Involving Family or Caretaker in Caring for the Cocaine Exposed Infant Reported by Occupational Therapists from Different Treatment Settings $(\underline{N}=17)$

\begin{tabular}{lcc}
\hline Method of Intervention & \multicolumn{2}{c}{ Treatment Setting } \\
\cline { 2 - 3 } & $\begin{array}{c}\text { Hospital } \\
\underline{n}=8\end{array}$ & $\begin{array}{c}\text { Outpatient } \\
\underline{n}=9\end{array}$ \\
\hline Family Training and Education & 8 & 8 \\
Concern for Infant Home Environment & 5 & 0 \\
Involvement with Social Services & 4 & 0 \\
\hline
\end{tabular}


We are seeing fewer amounts of kids that are drug exposed but preventative measures are always the best key." "There are individual cases. Some families feel they would not be good caretakers though some families feel satisfied with the level of interaction [between the therapists and the families]."

Answers to Research Questions

What are the occupational therapy assessment techniques being performed on infants who have been exposed to cocaine in utero?

Occupational therapists reported using several different assessment tools in the evaluation of infants exposed to cocaine in utero. Occupational therapists reported using standardized assessments as well as generalized assessments. Twelve different standardized assessment tools were mentioned and eight different generalized assessment techniques. A higher frequency of occupational therapists providing treatment within a hospital setting reported using generalized assessment techniques, whereas occupational therapists providing treatment from outpatient settings more frequently reported using standardized evaluation tools. Occupational therapists based in hospital settings made some negative comments regarding use of standardized evaluations. Clinical observation was overall the most frequently used assessment tool as reported by occupational therapists treating infants exposed to cocaine in utero.

What are the intervention techniques used by the occupational therapists in the treatment of infants that have been exposed to cocaine in utero?

Occupational therapists reported on many treatment approaches and treatment techniques used to treat infants exposed to cocaine in utero. Occupational therapists reported on three different treatment approaches and fourteen different treatment techniques. Occupational therapists based in 
hospital settings reported many treatment techniques. Occupational therapists interviewed who were based in outpatient settings reported more frequently on treatment approaches rather than specific treatment techniques. When infant intervention data were combined, the NDT approach remained the most reported treatment approach. Most of the occupational therapists interviewed reported that treatment techniques used with infants exposed to cocaine in utero are not unique to the cocaine exposed infant population and any infant having similar symptoms as a cocaine exposed infant would be treated similarly.

How are the family, caretaker, environment, and home situation considered in the occupational therapist's treatment of the infant exposed to cocaine in utero?

Occupational therapists reported having a high degree of interaction with families of infants exposed to cocaine in utero and found family training to be a very important part of treatment. In addition to commenting on family education, occupational therapists interviewed who were based in hospital settings commented on the infant's home environment and the occupational therapists' close involvement with social work concerning the infant and family issues. 


\title{
CHAPTER 4
}

\section{DISCUSSION, PROFESSIONAL IMPLICATIONS, RECOMMENDATIONS FOR FURTHER RESEARCH, AND SUMMARY}

\begin{abstract}
Discussion
This study examined assessment and intervention techniques utilized by occupational therapists when treating infants exposed to cocaine in utero. Previous studies have shown that infants exposed prenatally to cocaine are at risk for developmental and learning disabilities (Elliott, 1991). This indicates a need for intervention by occupational therapists. In addition, this study examined ways in which the families are involved in the treatment process and in the care of the infant exposed to cocaine. A discussion of the results follows.

\section{Research Question One: Assessments}

Information regarding the assessment techniques that occupational therapists reported using with infants exposed to cocaine in utero appeared to be contingent upon the setting in which the occupational therapist worked. $A$ higher frequency of occupational therapists providing treatment within a hospital setting reported using generalized assessment techniques, whereas occupational therapists providing treatment from outpatient settings more frequently reported using structured or standardized evaluation tools. The rationale surrounding this was suggested by the findings of this study. Infants that are seen in a hospital setting for occupational therapy intervention are in a more acute state of insult, are less medically stable, and have decreased endurance. It would follow that the infant might be unable to tolerate the time
\end{abstract}


involved in a standardized evaluation. Shorter and more generalized evaluation techniques may be more appropriate. The four generalized assessment techniques most reported by occupational therapists in hospital settings were: 1) observation of behavioral response, 2) assessment of motor development, 3) feeding assessment, and 4) clinical observation. Standardized assessments were mentioned less frequently by occupational therapists based in hospital settings. Occupational therapists in these settings made some negative comments regarding use of standardized evaluations stating that these tests were "too long" or "too hard on the babies." In the acute stage of illness in the hospital setting, standardized assessments may not be a practical choice. It may be more appropriate to use generalized assessments to get an overall picture for treatment.

The literature supports these responses. Hanft (1988) stated that comprehensive assessments are important and should examine development in physical, cognitive, and psychosocial domains. Though Schneider et al. (1989) suggested more specific infant assessments, Schneider addressed the areas of infant behavior and infant motor control as common problem areas when treating the infant exposed to cocaine in utero.

For occupational therapists based in outpatient settings, the most frequently reported assessment tool was clinical observation reported by all nine occupational therapists interviewed. Generalized assessments were reported less frequently by occupational therapists treating from outpatient settings. In an outpatient treatment setting the infant would be more medically stable, older, and have greater endurance. In this state the infant would be able to tolerate a longer, more structured, standardized evaluation. The most frequently reported 
standardized assessment reported by outpatient occupational therapists interviewed was the Gesell Developmental schedules. This was in agreement with Denton (1986) who examined intervention for the failure to thrive infant population who have a similar presentation to infants exposed to cocaine in utero. Schneider et al. (1989), however, preferred the Brazelton Neonatal Assessment Scale in the infancy period to assess infant function and beyond the newborn period the Movement Assessment of Infants (MIA) which provides qualitative and quantitative assessment in the first year of life. Though the Brazelton Neonatal Assessment Scale was mentioned by a few occupational therapists it did not appear to be the assessment of choice.

Upon review of the literature, many authors agreed with the importance of integrating the assessment of the family and infant home environment in the initial assessment. Smith and Deitch (1987) and Windeguth and Urbano (1989) stressed the importance of including family intake interviews including family history, family lifestyle and home environment into the initial assessment. One third of the occupational therapists interviewed in this study who were based in outpatient settings reported using a questionnaire as an assessment tool concerning the infant's behaviors and motor observations completed by the infant's parents or foster parents. None of the therapists interviewed who work in hospital based settings reported using a parent interview as an assessment tool, though this may have been due to how the question was presented.

When all data were tabulated, clinical observation was overall the most frequently used assessment tool as reported by occupational therapists treating infants exposed to cocaine in utero. Unlike other assessment tools reported by 
occupational therapists from different treatment settings, this assessment tool appeared to be consistent and treatment setting was not a factor.

\section{Research Question Two: Intervention}

To interview question four, occupational therapists reported on common treatment techniques used to treat infants exposed to cocaine in utero. Both treatment approaches and treatment techniques were reported. Treatment approaches are models of treatment which may include several different treatment techniques based on the principles of that model and treatment techniques are a specific method of treatment.

Occupational therapists based in hospital settings reported many treatment techniques. The four most frequently mentioned techniques included a) infant calming, b) feeding, c) parent education, and d) infant environmental control. This was in agreement with Schneider et al. (1989) who stressed that proper handling of the infant is essential to improve the infant's state control and to facilitate appropriate motor patterns. Techniques such as swaddling in a blanket and slow rocking can calm the infant and bring the infant to a visually alert state to make interaction with the caregiver possible. In addition, Schneider et al. emphasized parent education as of great importance to enhance normal infant development and ensure a strong parent-infant bond. Also, Gorga (1989) noted that occupational therapists work to facilitate function with infants in early intervention by enhancing motor control, sensory modulation, and socialemotional development.

Occupational therapists interviewed who were based in outpatient settings reported on more treatment approaches than specific treatment techniques. Treatment approaches tend to be more generalized than specific treatment 
techniques and those reported by occupational therapists included Neurodevelopmental Technique (NDT), Sensory Integration (SI), and Developmental approach. These treatment approaches are based on theories in occupational therapy. Though each approach has different methods, each has similar goals which are normalizing infant and child responses to the environment and facilitating normal development in the child (Kielhofner, 1992). Though the literature did not specifically address these techniques in association with infants exposed to cocaine in utero, these techniques are frequently used with infants and children with central nervous system damage.

Occupational therapists based in hospital settings took more time to explain their treatment techniques and the techniques explained were more complex. This may be due to the fact that the infant is in a more acute state of illness in the hospital and the focus of occupational therapy was to normalize the responses of the infant exposed to cocaine by focusing on treatment techniques such as environmental control and infant calming. In an outpatient setting, occupational therapists had more direct responses and responses were more consistent. At this time the infant is older and more stable and there can be more focus on NDT or SI approaches for behavior management and less focus on issues such as feeding and calming. When infant intervention data were combined, the NDT approach remained the most reported treatment approach reported.

\section{Research Question Three: Family and Environment}

In interview question six occupational therapists reported on the level of involvement they felt they had with infant caregivers and the infant's environment. In general, occupational therapists reported having a high degree 
of interaction with families of infants exposed to cocaine in utero. All but one occupational therapist interviewed reported the importance of interaction with infant caregivers and in most cases reported that these interactions were favorable. Most occupational therapists interviewed found family training to be a very important part of treatment and integrated this into their treatment plan and goals. Occupational therapists reported spending time training families to deal with infant behaviors and difficulties with the infant. Goals were to promote bonding between parent and infant, to teach parents how to look for signs of distress, to address feeding issues, to develop home programs, and to discuss social considerations. The findings of this study support Dunn (1989), Gorga (1989), and Hanft and Humphry (1989) who reported that occupational therapy services for infants include family services to aid the adult caregiver in the care and facilitation of the development of the child. In addition, Schneider et al. (1989) emphasized the importance of parent education and that parent education should begin early. Specific techniques discussed included educating caregivers on common signs of infant distress such as overstimulation, and stressed that caregivers should perform a repeat demonstration of all learned activities.

In addition to commenting on family education, occupational therapists interviewed who were based in hospital settings commented on the infant's home environment and occupational therapists' close involvement with social work concerning the infant and family issues. Over half of the occupational therapists interviewed from this setting voiced concern for the infant's home environment and noted more frustrations than functional strategies. Frustrations 
included poor follow-up with parents and the lack of control occupational therapists felt after the infant left the hospital.

Professional Implications and Recommendations for Further Research

This study examined assessment and treatment techniques reported by occupational therapists in the treatment of infants exposed to cocaine in utero. The occupational therapy literature has not specifically addressed the treatment of infants exposed to cocaine in utero. The allied health literature, however, has addressed the symptomatology, assessment, treatment, and risk for developmental delay for infants exposed to cocaine in utero. The occupational therapy literature stressed the importance of occupational therapy in early intervention with infants with developmental delay or who are at risk for developmental delay and the importance of integrating the family in the treatment of the infant. This pilot study as an important addition to the occupational therapy literature clarifies some specifics about the role of occupational therapists in the treatment of infants exposed to cocaine in utero. The information reported in this study is useful as a teaching tool and as a reference for occupational therapists treating infants exposed to cocaine in utero.

A follow-up study involving a larger sample size over a larger geographic area would yield a more comprehensive picture of assessment and intervention techniques used by occupational therapists in various treatment settings. Another study could examine the clinical reasoning that led to the use of reported assessment and treatment techniques. A third study might examine the effectiveness of intervention to improve the medical condition, function, and coping behaviors of the infant and the family on a short and long term basis. 
This study did not examine influences and roles of other treatment team members or their treatment methods for infants exposed to cocaine in utero. Thus, the overall treatment of the infant was not assessed but is limited to procedures administered by occupational therapists. Since the team approach is important when treating infants exposed to cocaine in utero, a useful research study could examine the impact of the entire treatment team in the assessment and treatment of infants exposed to cocaine in utero.

\section{Summary}

This study examined how occupational therapists address the needs of infants exposed to cocaine in utero. Many authors have shown that in utero cocaine exposure can affect the infant in negative ways. Schneider et al. (1989) described the negative effects of in utero cocaine exposure as causing problems with infant motor control, behavior, and social development (infant-caregiver bonding). The occupational therapy literature has not specifically addressed the occupational therapist's role in the treatment of infants exposed to cocaine in utero. The purpose of this pilot study was to begin to fill that gap in the literature. This study examined the use of occupational therapy assessment tools, and treatment techniques with infants exposed to cocaine in utero as well as how the caretaker and infant environment are considered in the treatment of the infant exposed to cocaine in utero.

Occupational therapists interviewed were based in hospital and outpatient settings. Some responses to interview questions were contingent upon the treatment setting and others were not. Demographic information gathered from interviews described how occupational therapists received referrals for infants exposed to cocaine in utero and how occupational therapists identified that the 
infant had been exposed to cocaine in utero. Occupational therapists based in hospital settings relied most frequently on the physician for referrals. In an outpatient treatment setting most occupational therapists interviewed reported receiving referrals for infants exposed to cocaine in utero from the regional centers or Developmental Disability Center. The method by which occupational therapists identified whether the infant was diagnosed with cocaine exposure was consistent and treatment setting was not a factor. Most occupational therapists gathered this information from the report of a urine toxicology screen of the infant at the time of birth found in the medical chart. The consistency in the data collected is most likely due to the fact that this information was passed from inpatient records or those found in the neonatal intensive care unit to the outpatient records and was not changed or affected.

Occupational therapists in this study who are treating infants exposed to cocaine in utero reported using both standardized and generalized assessment tools when evaluating infants exposed to cocaine in utero. Occupational therapists providing treatment from hospital settings tended to utilize more generalized assessment tools while therapists based in outpatient settings utilized more standardized assessments. Clinical observation, however, was the most frequently reported assessment tool.

Treatment techniques reported by occupational therapists treating infants exposed to cocaine in utero had different responses based on the therapist's treatment setting. Occupational therapists in hospital settings reported more specific treatment techniques that focused on direct infant intervention as well as the importance of parent education and training in the care of the infant exposed to cocaine in utero. This was in agreement with the medical literature and 
occupational therapy literature in stressing the importance of family-centered care in the care of the infant exposed to cocaine in utero.

Most of the occupational therapists interviewed reported that treatment techniques used with infants exposed to cocaine in utero are not unique to the cocaine exposed infant population. Any infant having similar symptoms or signs would be treated similarly. Thus the symptoms are treated not the diagnosis. Those few occupational therapists who reported that treatment techniques were unique to the cocaine exposed infant population stressed that though cocaine exposed infants present somewhat similarly to other infant diagnoses there is usually an additional component (such as a behavioral component) which makes the approach to treatment unique for this population. Recommendations for further research include replicating this study with a larger sample examining the clinical reasoning behind reported assessment and treatment techniques, and studying the roles of the entire treatment team to gain an overall view of the care of the infant exposed to cocaine in utero. 


\section{References}

Allen, L. F., Palomares, R. S., Deforest, P., Sprinkle, B., \& Reynolds, C. R. (1991). The effects of intrauterine cocaine exposure: Transient or teratogenic? Archives of Clinical Neuropsychology, 6, 133-146.

American Occupational Therapy Association. (1986). Roles and functions of occupational therapy in early childhood intervention. The American Journal of Occupational Therapy, 40, 835-838.

Asher, I. E. (1989). An Annotated Index of Occupational Therapy Evaluation Tools. Rockville: The American Occupational Therapy Association, Inc.

Bauer, A. M. (1991). Drug and alcohol exposed children: Implications for special education for students identified as behaviorally disordered. Behavioral Disorders, 17(1), 72-79.

Brazelton, B. T. (1984). Neonatal behavioral assessment scale, $2^{\text {nd }}$ Edition. Philadelphia: Lippincott.

Chasnoff, I. J. (1988). Drug use in pregnancy: Parameters of risk. The Pediatric Clinics of North America, 35, 1403-1412.

Chasnoff, I. J. (1991). Drugs, alcohol, pregnancy, and the neonate: Pay now or pay later. Journal of the American Medical Association, 266, 1567-1568.

Chiu, T. T., Vaughn, A. J., \& Carzoli, R. P. (1990). Hospital costs for cocaine-exposed infants. Journal of Florida M. A. 77, 897-900.

Denhoff, E. (1981). Current status of infant stimulation for enrichment programs for children with developmental disabilities. Pediatrics, 67, 32-37.

Denton, R. (1986). An occupational therapy protocol for assessing infants who fail to thrive. The American Journal of Occupational Therapy, 40, 352-358. 
Dunn, W. (1989). Occupational therapy in early intervention: New perspectives create greater possibilities. The American Journal of Occupational Therapy, 43, 717-721.

Elliott, K. T. (1991). Crack babies: Here they come, ready or not. Journal of Instructional Psychology, 18(1), 60-64.

Gesell, A. (1975). Developmental diagnosis. Hagerstown: Harper \& Row.

Gorga, D. (1989). Occupational therapy treatment practices with infants in early intervention. The American Journal of Occupational Therapy 43, 731-736.

Hanft, B. (1988). The changing environment of early intervention services: Implications for practice. The American Journal of Occupational Therapy, 42, 724-731.

Hanft, B. E., \& Humphry, R. (1989). Training occupational therapists in early intervention. Infants and Young Children, 1(4), 54-65.

Humphry, R. (1989). Early intervention and the influence of the occupational therapist on the parent-child relationship. The American Journal of Occupational Therapy, 43, 738-741.

Kielhofner, G. (1992). Conceptual foundations of occupational therapy. Philadelphia: Davis.

McCance-Katz, E. F. (1991). The consequences of maternal substance abuse for the child exposed in utero. Psychosomatics, 32, 268-274.

Phibbs, C. S., Bateman, D. A., \& Schwartz, R. M. (1991). The neonatal costs of maternal cocaine use. Journal of the American Medical Association, 266, 1521-1526. 
Richardson, G. A., \& Day, N. L. (1991). Maternal and neonatal effects of moderate cocaine use during pregnancy. Neurotoxicology and Teratology, 13 , 455-460.

Sameroff, A. J., \& Fiese, B. H. (1990). Transactional regulation and early intervention. In S. J. Meisels \& J. P. Shonkoff (Eds.), Handbook of early childhood intervention (pp. 119-149). New York: Cambridge University Press.

Schaaf, R. C., \& Mulrooney, L. L. (1989). Occupational therapy in early intervention: A family-centered approach. The American Journal of Occupational Therapy, 43, 745-754.

Schneider, J. W., Griffith, D. R., \& Chasnoff, I. J. (1989). Infants exposed to cocaine in utero: Implications for developmental assessment and intervention. Infants and Young Children, 2(1), 25-36.

Singer, L. T., Yamashita, T. S., Hawkins, S., Cairns, D., Baley, J., \& Kliegman, R. (1994). Increased incidence of intraventricular hemorrhage and developmental delay in cocaine-exposed, very low birth weight infants. The Journal of Pediatrics, 124, 765-771.

Schutter, L. S., \& Brinker, R. P. (1992). Conjuring a new category of disability from prenatal cocaine exposure: Are the infants unique biological or care taker casualties? Topics in Early Childhood Special Education, 11(4), 84111.

Smith, J. E., \& Deitch, K. V. (1987). Cocaine: A maternal, fetal, and neonatal risk. Journal of Pediatric Health Care, 1, 120-124.

Urbscheit, N. (1990). Cerebellar dysfunction. In D. Umphred (Ed.), Neurological Rehabilitation (pp. 597-618). St. Louis: Mosby. 
Umphred, D. \& McCormack, G. (1990). Classification of common facilitatory and inhibitory treatment techniques. In D. Umphred (Ed.), Neurological Rehabilitation (pp. 111-161). St. Louis: Mosby.

Windeguth, B. J. von, \& Urbano, M. T. (1989). Cocaine-abusing mothers and their infants: A new morbidity brings challenges for nursing care. Journal of Community Health Nursing, 6 , 147-153.

Zuckerman, B., \& Frank, D. A. (1994). Prenatal cocaine exposure: Nine years later. The Journal of Pediatrics, 124, 731-733. 
Appendix A

Verbal Consent Form 


\section{Verbal Consent Statement}

1) You are free to ask any questions concerning the study during this phone interview.

2) You may stop the interview at any time if you change your mind about participating.

3) The information gathered from this interview will be used in a research study.

4) The research study may be published, but your name will not be connected with the data in any way. 
Appendix B

Interview Questions 
Interview Questions

1) How and from whom do you get a referral for an infant who has been exposed to cocaine in utero?

2) How do you know that the infant has been exposed to cocaine?

3) What sort of initial assessments do you perform?

4) What intervention strategies or treatment methods do you use?

5) Are the treatment techniques being used unique to the cocaine exposed infant population?

6) How is the infant's family, caretaker or environment considered? 